\title{
ETHONOBOTNICAL AND MEDICINAL IMPORTANCE OF OCIUMUN AMERICANUM
}

\author{
Sharada K. Ulhe- Deshmukh \\ Mahatma Fule Arts, commerce \& Sitaramji Choudhari Science College, \\ Warud, dist-Amravati \\ E-mail botanysharu@,rediffmail.com
}

Communicated : 14.12.19

Revision : 16.12.19 \& 03.01.2020

Accepted : 22.01.2020

Published: 30.01 .2020

\begin{abstract}
:
Ocimum americanum plant was collected from Panjabrao Deshmukh Krushi vidyapeeth (PDKV) forest of Nagpur district. This plant belongs to family -Lamiaceae and is commonly known as "Subja" which is wild, evergreen, perennial herb; showing creeping habit up to $80 \mathrm{~cm}$. Roost is typically tapped root, aerial, and weak herbaceous. Stem shows adventious root on node; stem weak branched, branching recemose as well cymose, young branches angular cylindrical. Leaves covered by hairs, leaves simple, estipulate opposite decussate, sub sessile elliptic lanceolate lamina ovate, unicostate with crenate margin and acute apex gland dotted below. Fresh leaves were shaded dried and 50gm powder is used. To search novel active compounds from plant origin and to access the valuable thereupatic properties with minimum side effects, application of advanced method like GC-MS computational techniques plays an important role in the development of drug of interest. 4 compounds were identified in aerial parts of leaves of Ocimum americanum. Out of the 4 compounds identified in ethanolic extract, 3,3-dimethyl-2-(phenylsenyl)-,2,2,2-trifluoro-1-(9-anthracenyl) ethyl ester. (Butanoic acid), Diacetato[1,2-bis(diclohexylphosphino)ethane, dibromi(E) (tetrakis(trimethylphosphine, 10,10'-diselenodi(Decanoic acid). It was found that the constituents differed in quantity of Ocimum americanum in the Nagpur region which may be due to the local geographical difference. Aromatic oil is found in 5\% in 3gm of dry weight of powder of leaves of Ocimum americanum. Conclusion: The effects of $O$. americanum may delay the development some life threating complications and this work stimulates the researchers for further research on the potential use of this medicinal as well as ethonobotnical plants having pharmaceutical potential.
\end{abstract}

Key words: - Ocimum americanum (L.), GC-MS, compounds. Photochemicals

\section{INTRODUCTION:}

According to world health organization (WHO) variety of drugs are obtained from ethonomedicinal plants.In developed countries almost $80 \%$ of individuals depends on compounds derived from ethnomedicinal plant.In this regard properties,saftey \& efficiency of them should be investingated.1.Ethnobotany is systematic study of the relationship between plants and people.It is not simply the study of human use of plants rather ethonobotany locates plants within their cultural contex in particular socities.the impacts of modern human societies on traditional cultures and natural habitats have caused huge losses of individual species and profoundly disupted communites of species.The singnificance of ethnobotany and ethnomedicinal plant is mainfold.The study of indigenous food production and local medicinal knowledge may have practical implication for developing sastainble agriculture and discovery of new medicines.Ethnobotany also encourage an awarness of the link between biodiversity and culture diversity as well as a sophisticated understainding of the mutual influence of plants mutual influence of plants and human.the Global strategy for Plant conservation , a plant to save the world's Plant species-grew out of the Convention on Biological diversity and is being fed into government policy around the world.The GSPC hightlights the importance of plants and the ecosyetem services they provide for all life on earth and aims to ensure their consevation.The Global strategy for Plant consevation is a catalyst for working together at all levels-local national,regional and global-to 
understrand,conserve and use sustainbly the worlds's immense wealth of plant diversity whilst promoting awareness and building the necessary capcities for its implention.Ethnomedicinal plants consevation strategies need to be understood and planned for based on an understaiding of indigenous knowledge and practices $^{2}$. Gas chromatogrphy and Mass spectrum is one of the best method for to identify the plants chemical components. Ocimum americanum contain essential oil which is volatile organic strong smell substance and have great importance in pharmaceuticals industries.

\section{History And Description of Ocimum americanum.}

Lamiaceae family species are important for its medicinal properties among plants. Pushpangadan in 1995 has reported that the genus Ocimum has more than 160 species and is the largest genera in Lamiaceae family worldwide, of which about 65 species are native to Ocimum and the rest should be considered as synonyms ${ }^{3}$.Number of aromatic plants come under this family. Ocimum americanum (wild) belonging to the family of Lamiaceae, is a aromatic herb commonly called "Subja", found as weed in Africa, Asia-temperate and Asia - tropical countries. Ocimum americanum was first described by Linnaeus based on an illustration and description of plants growing in the Leiden botanic garden. Ocimum americanum (wild) plant contains essential oil which is alkaloids.

\section{MATERIAL AND METHODS:-}

\section{Collection of plant material}

India has great potential of biodiversity. The genus Ocimum americanum (L.) belongs to Lamiaceae family. Ocimum americanum(L). Ocimum americanum (L.) is a traditional medicinal plant distributed all over India mostly on waste lands,river banks and sides of paddy fields. Local name in Telugu: Kukkatulasi, Hindi: Kala tulasi, Tamil: Nayi tulasi,Malayalum: Kattu tulasi,Marathi subja and the trade name is Hoary basil. The plant is a much branched strongly aromatic herb,branches are grooved and pubescent. Leaves are elliptic and ovate. Flowers are in whorls, white or cream in colour as terminal racemes. Fruits are nutlets, oblong and black. Ocimum americanum leaves were collected from in and around Panjabrao Deshmukh Krushi vidyapeeth (PDKV) forest of Nagpur district. ,. The plant was identified by the Plant systemic laboratory Department of Botany,R.T.M.University Nagpur Maharastra.GCMS Analysis - The test plant extracts were subjected to GC-MS analysis at laboratory's (IIT Bombay) Sophisticated Analytical Instrument Facility (formerly RSIC), Indian Institute of Technology, Powai, Mumbai - 400076, India.

\section{RESULTS AND DISCUSSION}

The present investigation was carried out on plant Ocimum americanum of Lamiaceae family to study the presence of medicinally active phytochemicals in the leaves. The chemical composition of the essential compounds from the leaves of Ocimum americanum (L.) Poit collected from campus and PDKV forest which experienced different climatic and geographic circumstances, were determined by GC-MS. It has been already reported by various workers. As seen in the table- 1, different compounds were determined from the leaves of Ocimum americanum (L.) Poit. The present investigations concluded that the leaf o Ocimum americanum $\mathrm{f}$ contains chemical compounds. These chemicals are widely used in Ayurvedic traditional medicines as well as cosmetics industry.

Ocimum americanum in chemical compounds and herbal ingredients, and it has been said that 70$80 \%$ of the world's population relies on some from of non-conventional medicine ${ }^{4}$ and around $25-40 \%$ of all prescription drugs contain active ingredients derived from plants in theUnited States ${ }^{5}$.

\section{Medicinal importance of Ocimum americanum;}

1. In traditional medicine, O. americanum holi basil is used for several ailments.

2. Decoctions are used for coughs; pounded leaves are placed on the forehead to relieve catarrh or on the chest for respiratory problems. 
3. the whole plant is used in baths to treat rheumatism, renal colic and calcifications.

4. More recently, the plant has been listed as a potential medicine against cancer.

5. Aromatic oil is found in 5\% in 3gm of dry weight of powder of leaves of Ocimum americanum.

6. An essential oil can be extracted from plants leaves of $O$. americanum is used in soap and cosmetics. It has been reported to exhibit fungitoxic properties (without phytotoxic side-effects).The oil contains citral, camphor, and methyl-cinnamate.

7. O. americanum has been planted on a large scale in the Common wealth of Independent States, Kenya and Pakistan for the production of camphor, which has medicinal and industrial applications (celluloid, fireworks).

8. O. americanum used to treat inflammatory and allergic conditions.

The leaves past is used in tretment of skin deaseses,it is also appplied on wound and burns that are not healing well.

\section{Detection of Oil in Ocimum americanum}

Ether is continuously volatilized, condensed and then allowed to pass through the sample to extract ether soluble materials. When the process is completed the either is distilled, collected in another container, remaining crude fat is dried, weight and percent oil is calculated. I got 5\% oil in leaves of Ocimum americanum Weight of sample $3 \mathrm{gm}$ dry leaves powder.

\section{CONCLUSION:}

The study concluded that Ocimum americanum and its habitat less but its own reproductive strategies.

Most of the medicinal claims are centered on flower

and inflorescence of the plant. The whole plant and leaves, are also administered in a few specifi c clinical conditions. The analysis of all the claim s clearly indicates thepotential of the plant to be an excellent analgesic, antipyretic and anti infla mmatory drug which needs to, be,validated, thoro ugh preclinical and safety and efficacy trials. The present GC-MS screening are an essential tools for confirmation of the results and it may serve as pavements for the researcher to select a group of plants having similar chemical constituents and their detailed investigation regarding their chemistry and functions is required, so that they can be used in allopathic or in Ayurvedic medicine as well as cosmatics industry.

\section{REFERENCES}

Dowound G T M and El-Morsy T H (2012); Phytochemical microbial studies of Petrea volubilies L J American Science 8(8): 202-208.2)

C.Kalu and. Anifowoshe E.I (2003) Ethnomedicinal uses of plants the Ekitis in Irepodun

Berkes, Fikret; Turner, Nancy J.(2006)."Knowledge, Learning and the Evolution of Conservation Practice for SocialEcological System Resilience. Human Ecology 34(4): 479-494.doi:10.1007/s 10745-006-9008-2."

Erik, S. and B. Tarikahya (2004): Turkiye Florasi Uzerine, Kebikec. 17: 139 - 163

Endangered Plants and Ecosystems -Plants Conservation Derived Medications

Chopra, R. N., Nayar, S. L. and Chopra, I.C. (2002): Glossary of Indian Medicinal Plant. National Institute of Science Communication and Information Resources, New Delhi Council of Scientific and Industrial Research (CSIR). Pp. 153.

Mangathayaru, K., D. Thirumuragan; P. S. Patel; D. V. Pratap; D. J. David and J. Karthikeyan (2006): Isolation and identification of nicotine from Leucas aspera (wild). Indian J. Pharm. Sci. 68: $88-90$.

Arceusz, Agnieszka, lwona; Marek (2010),"Identification Of diversity in elements content in medicinal plants belonging to different plants to different

Boonklinkajorn, P. \& Chomchalow, N., 1968. Preliminary study of the effect of plant density on the yield of Ocimum spp. Thailand Institute of Scientific and Technological Research (TISTR), Bangkok, Thailand. Research Project No 11/18. Technical Report No 3. 18 pp. 
Darrah, H.H., 1974. Investigation of the cultivars of the basils (Ocimum). Economic Botany 28(1): 63-67.

Keng, H., 1978. Labiatae. Ocimum. In: van Steenis, C.G.G.J. et al. (Editors), 1950- . Flora
Malesiana. Series 1. Vol. 8. Sijthoff \& Noordhoff International Publishers, Alphen aan den Rijn, the Netherlands. pp. 376-379.
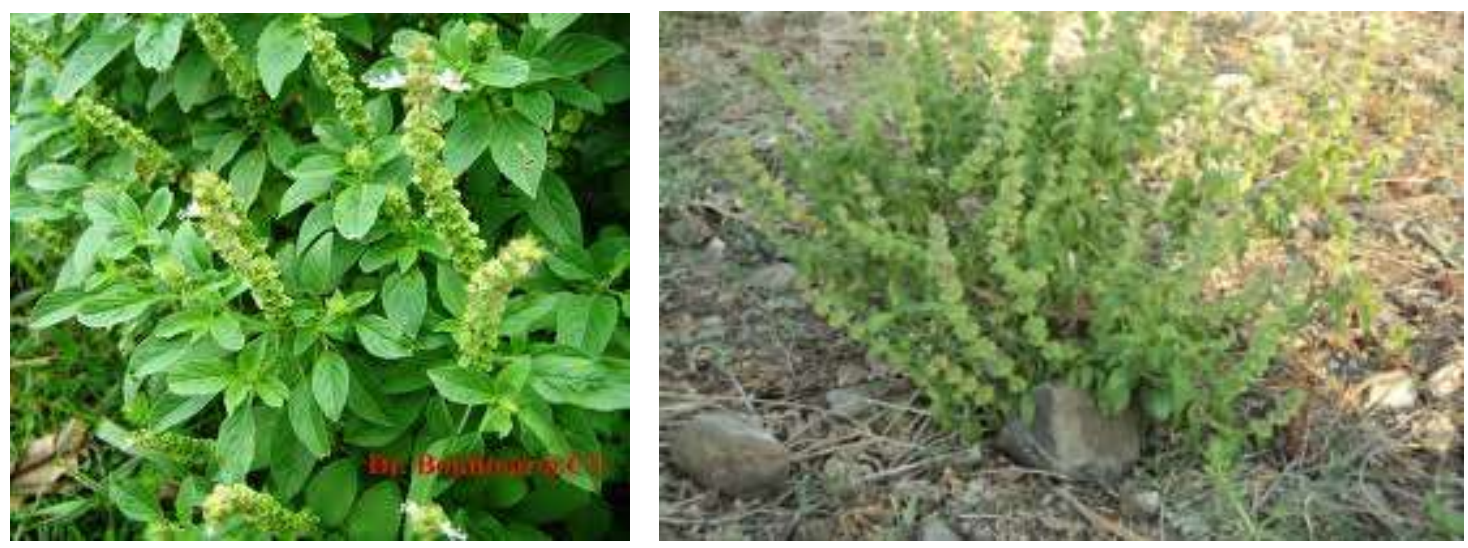

Fig-Habit of Ocimum americanum

Table No. : 1 The chemical Composition of Ocimum americanum (wild) Linn.

\begin{tabular}{|c|c|c|c|c|c|}
\hline $\begin{array}{c}\text { S. } \\
\text { N. }\end{array}$ & R.T & Name of compound & $\begin{array}{c}\text { Molecular } \\
\text { formula }\end{array}$ & $\begin{array}{c}\text { Mol. } \\
\text { Weight }\end{array}$ & $\begin{array}{c}\text { Peak } \\
\text { Area }\end{array}$ \\
\hline 1 & 18.3 & $\begin{array}{c}3,3 \text {-dimethyl-2-(phenylsenyl)- } \\
2,2,2 \text {-trifluoro-1-(9- } \\
\text { anthracenyl) ethyl ester. } \\
\text { (Butanoic acid) }\end{array}$ & $\mathrm{C}_{28} \mathrm{H}_{25} \mathrm{~F}_{3} \mathrm{O}_{2} \mathrm{Se}$ & 483 & 141200 \\
\hline 2 & 18.3 & $\begin{array}{c}\text { Diacetato[1,2- } \\
\text { bis(diclohexylphosphino)ethane] }\end{array}$ & $\mathrm{C}_{30} \mathrm{H}_{54} \mathrm{O}_{4} \mathrm{P}_{2} \mathrm{Pd}$ & 584 & 141200 \\
\hline 3 & 22.8 & $\begin{array}{c}\text { Osmium dibromi(E) } \\
\text { (tetrakis(trimethylphosphine }\end{array}$ & $\mathrm{C}_{12} \mathrm{H}_{36} \mathrm{Br}_{2} \mathrm{OSP}_{4}$ & 488 & 66375 \\
\hline 4 & 22.8 & $\begin{array}{c}10,10 \text { '-diselenodi-(Decanoic } \\
\text { acid) }\end{array}$ & $\mathrm{C}_{20} \mathrm{H}_{38} \mathrm{O}_{4} \mathrm{Se}_{2}$ & 410 & 66375 \\
\hline
\end{tabular}




\section{Graphical Representation of Ocimum americanum}
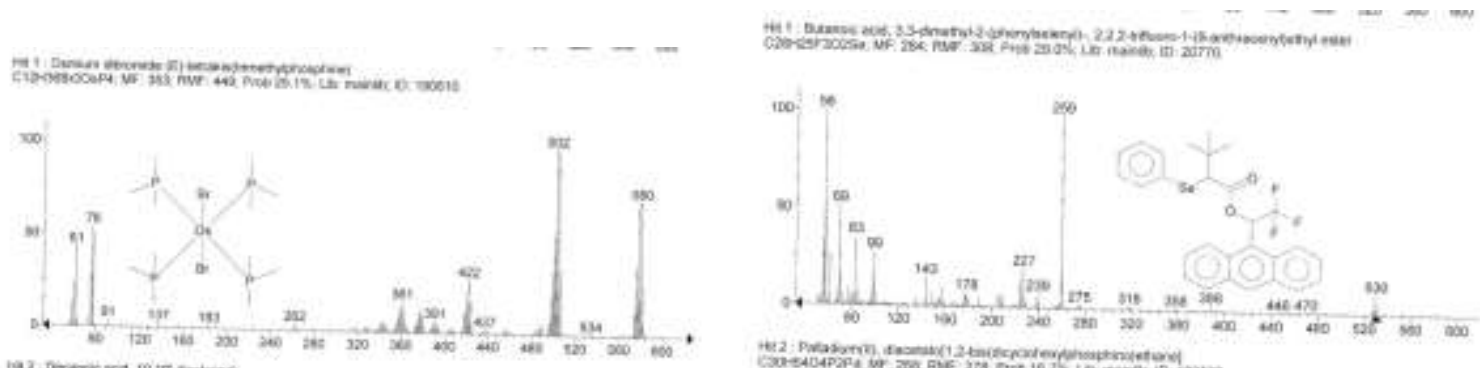

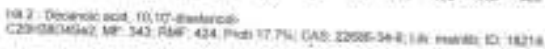
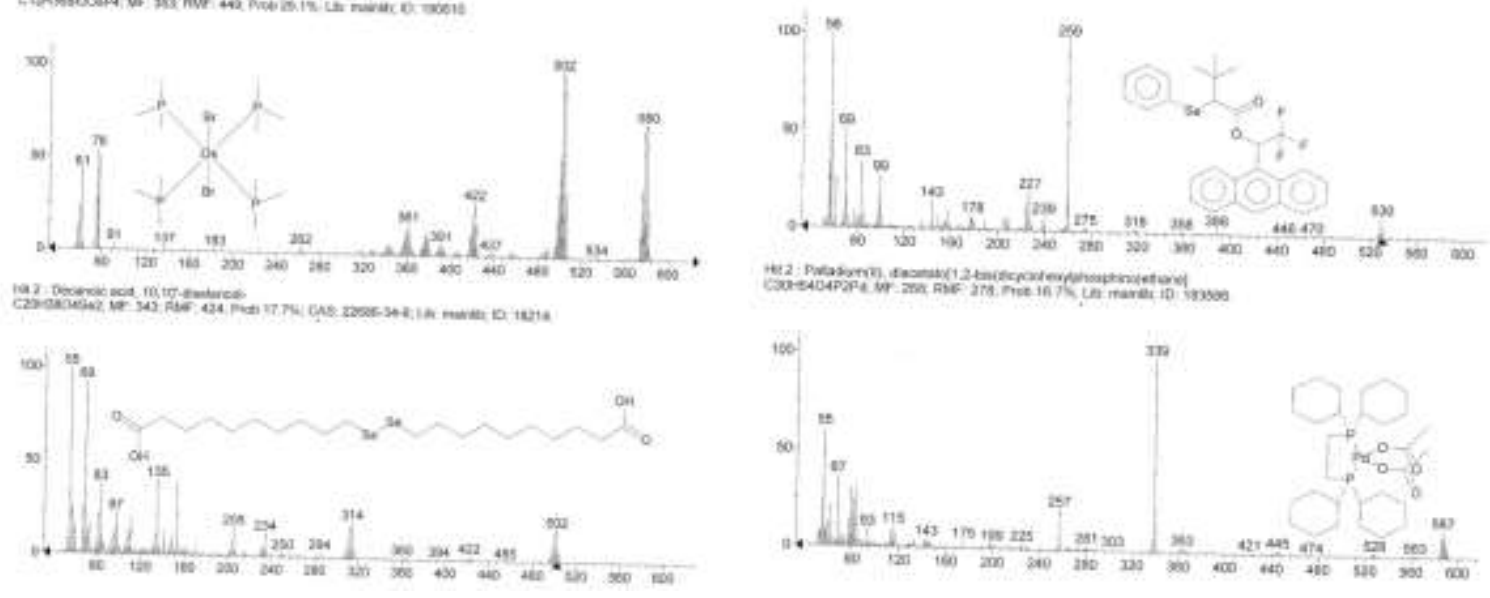

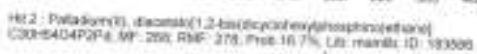

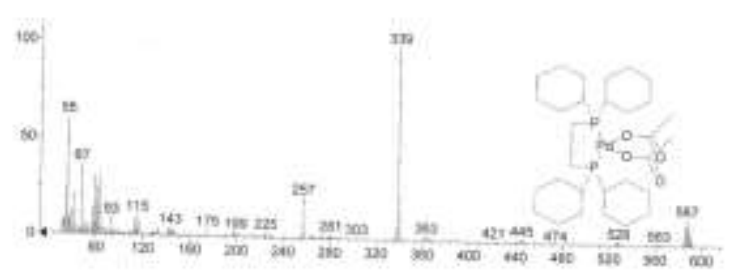

Table No. 2- Analysis of oil percentage in Leaves of Ocimum americanum

\begin{tabular}{|c|c|c|c|c|}
\hline $\begin{array}{c}\text { No. } \\
\text { Plant }\end{array}$ & Plant Sample Name & $\begin{array}{c}\text { Empty flask } \\
\text { weight }\end{array}$ & $\begin{array}{c}\text { Empty flask oil } \\
\text { weight }\end{array}$ & $\begin{array}{c}\text { Oil percentage } \\
\text { of leaf }\end{array}$ \\
\hline 5. & Ocimum americanum & $119.700 \mathrm{gm}$ & $119.550 \mathrm{gm}$ & $5 \%$ \\
\hline
\end{tabular}

